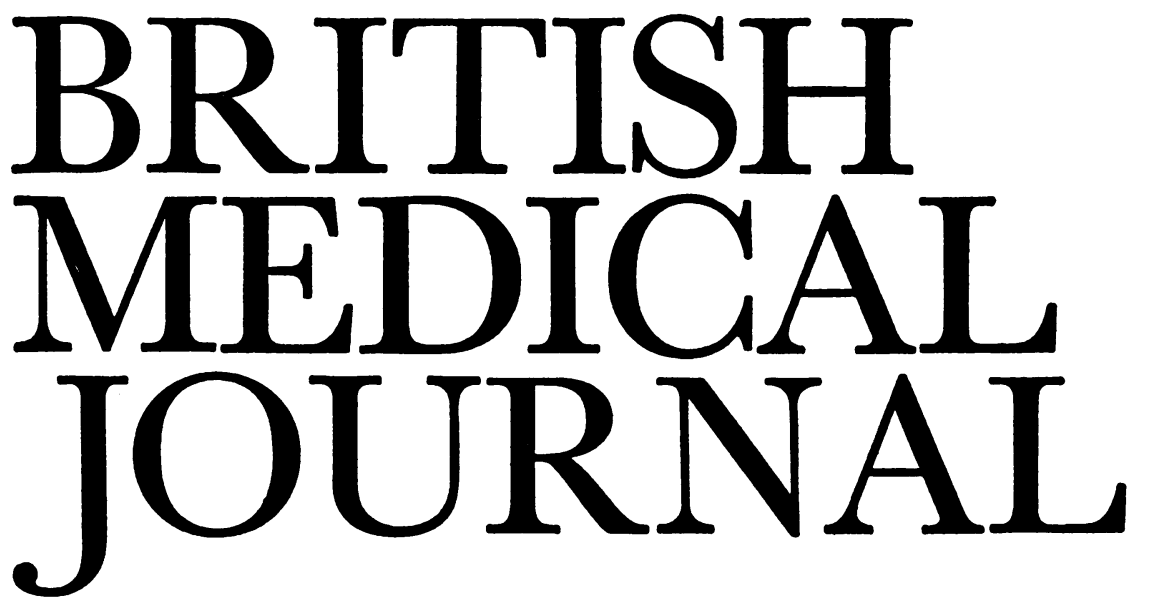

LONDON SATURDAY 27 JANUARY 1973

\title{
Ethical Criteria
}

The medical secrets of patients have never been of so much interest to so many people as they are today. Clinicians, epidemiologists, geneticists, biochemists, social workers are all taking part in researches designed to improve diagnosis and treatment. For some of them indeed the research is a way of life; for nearly all it is a response to a strongly felt impulse to improve man's lot and advance their own. Their eagerness to make observations and collect data is understandable, and the results show it often to be commendable. But in the process what happens to the confidence that a patient entrusts to his doctor? The medical profession throughout the ages has regarded this trust as sacred. It is in this context that the report from the Medical Research Council published this week in the B.M.F. at page 213 needs to be considered.

When it gave evidence to the Government Committee on Privacy, whose report appeared last year, ${ }^{1}$ the M.R.C. mentioned that it was attempting to draw up a code of practical and ethical guidance on access to personal medical information and the maintenance of confidentiality. The present statement is the result of its labours, and it deserves a warm welcome. In particular, it goes far to set at rest doubts expressed in these columns ${ }^{2}$ about the handling of confidential information without the knowledge of the patient from whom it came. The M.R.C. told the Committee on Privacy that a practice has evolved whereby a doctor may disclose personal information about a patient to medical research workers without the patient's consent. The safeguards under which information of this kind may be communicated are set out in this week's statement. In essence they are that the information must be passed, under the seal of confidence, only to members of the medical profession, who are bound by their ethical traditions and subject to the discipline of the General Medical Council, or to non-medical people collaborating with medical practitioners or specially authorized by a medical committee to receive the information. And the overriding consideration, says the statement, must always be that no harm or distress will ensue for the individual and his family, and that the doctor-patient relationship will in no way be impaired.

The need to communicate confidential information is particularly evident in epidemiological research, which in the last 20 years has expanded so fruitfully into the study of nontransmissible diseases such as lung cancer, some industrial cancers, and cardiovascular disorders. For in this type of re- search the investigators are rarely the doctors who have the medical care of the patients they are studying. But the extension to this situation of the practical and ethical principles concerned with the control of epidemic infection is not so simple as the M.R.C. suggests.

The control of epidemics of infectious disease was achieved, the statement rightly says, in part through notification by family doctors to the medical officer of health. "Similarly," it goes on, "the control of non-infectious diseases may be assisted by the transfer of medical information between doctors." This too is incontestable, but the word "similarly" conceals an important difference. Man is gregarious and lives in communities. When he learnt the rationale of infection-sometimes intuitively before that-he acted through the community to prevent it from spreading. The individual members of a community yield some freedom of action by general assent for the good of their fellowmen. But coronary thrombosis, for instance, though it may be an epidemic disease is not an infectious disease, and there is no evidence that the community in Britain is yet ready to take quite the same view of non-transmissible as of infectious diseases. The battles over proposed legislation to fluoridate water supplies or to ban the medical use of heroin show that public opinion is divided to an extent that it is not over measures to control the spread of infection from man to man.

Thus the M.R.C.'s statement should be seen as something rather more novel than first sight would suggest. This is worth bearing in mind when medical researchers look to its code for guidance. No code alone can cover all the circumstances that may arise to puzzle or trouble an investigator's conscience. Because it was particularly aware of this the M.R.C. itself felt diffident for many years about issuing a code for research workers until the great expansion of medical research since the second world war made this inevitable. And neither the present code with its emphasis on research in the community nor the previous one ${ }^{3}$ with its emphasis on research on individual patients should be read as though they were legal documents. The honesty with which a medical investigator seeks valid consent from a patient and the use to which he puts a patient's confidences are judged by ethical, not legalistic, criteria, even though they may be moulded by a formal statement from such a respected authority as the Medical Research Council.

The announcement that the Medical Research Council is 
to set up a standing committee to watch over these ethical problems is as welcome as are its two codes. In these and other statements it has shown itself to be solicitous for the individual patient's welfare and guided by the strictest ethical criteria, while published reports of its research workers have always set an example of scrupulous conduct. This too is worth bearing in mind when researchers look for guidance in the codes. The M.R.C. practises to the high standards it preaches.

1 Committee on Privacy, Report, Cmnd. 5012. London, H.M.S.O., 1972. 2 British Medical fournal, 1972, 3, 189.

Medical Research Council, British Medical fournal, 1964, 2, 178.

\section{Glucagon and Growth Hormone}

There are several stimuli to the secretion of growth hormone. They include physical activity, stress, hypoglycaemia, a rise in blood amino-acids, administration of amphetamine or propranolol, and simply falling asleep at night or snoozing during the day. While the mechanisms by which these stimuli work are not fully understood, they may be used when investigating a patient suspected of having insufficient growth hormone.

A diagnosis of any pituitary hormone deficiency should be accepted only if the blood levels fail to rise during a potent stimulus to the hormone's release. This is particularly important when considering growth hormone, since it is in short supply and treatment with it is effective only in growthretarded children who lack it. Other forms of dwarfism do not respond. ${ }^{1}$ The detection of impaired secretion of growth hormone in adults may also be of diagnostic importance, since it is affected much earlier than corticotrophin or thyroid-stimulating hormone in most cases of progressive pituitary or hypothalamic disease, usually shortly after impairment of gonadotrophin secretion. ${ }^{2-4}$ Impaired secretion of growth hormone in an adult may therefore give early confirmation of a suspected pituitary or hypothalamic defect.

Undoubtedly the most reliable test procedure in investigating the pituitary reserve for growth hormone secretion is the insulin tolerance test. The induced hypoglycaemia in this test regularly causes secretion of growth hormone in healthy people provided the hypoglycaemia is adequate-that is, the blood sugar falls to less than $40 \mathrm{mg} / 100 \mathrm{ml}$ for at least 10 minutes and sympathetic activation is seen, such as sweating. Provided patients do not have cardiovascular disease or epilepsy the test is safe, but medical supervision is necessary in case glucose has to be administered intravenously. The test has advantages over others in that it takes only two hours to perform and the pituitary-adrenal reserve can be tested simultaneously, since plasma levels of cortisol should also rise during hypoglycaemia.

Since many clinicians do not wish to perform a hypoglycaemia test in young children and it is contraindicated occasionally in adults with ischaemic heart disease or epilepsy, some alternative tests for secretion of growth hormone have been developed. Thus children may be exercised or given large doses of Bovril by mouth. Adults are given intravenous infusions of arginine, but 48 hours' pretreatment with stilboestrol is necessary in men to sensitize the pituitary; unprepared, healthy men often fail to secrete growth hormone. 5 Unfortunately these stimuli are sometimes insufficient to cause adequate secretion even in healthy people, and therefore further possibilities have been considered.

A fall in raised blood sugar level will cause secretion of growth hormone even though the level it sinks to is not low enough itself to produce hypoglycaemic symptoms. It has therefore been suggested that the response of the growth hormone to the decline in blood sugar levels after the peak of an oral glucose tolerance test can be used as a test. ${ }^{6} \mathrm{~J}$. Roth and his colleagues in $1963^{7}$ first followed the rise in growth hormone which occurs after the administration of glucagon, and since then from time to time reports of the response of this hormone to glucagon have appeared. However, its value in pituitary investigation has been controversial. Some have stated that secretion of growth hormone responds directly to administration of glucagon independently of any blood sugar changes $; 8$ others have said that the responses are inconsistent and are related only to the stress of the nausea often induced by glucagon. 9 Enthusiastic supporters of the glucagon test maintain that the effect is specific, consistent, and direct, being independent of fluctuations in blood sugar. ${ }^{10}$ Describing the procedure, M. L. Mitchell and colleagues ${ }^{11}$ advised administration of $1 \mathrm{mg}$ of glucagon subcutaneously, with blood sampling over the subsequent three hours. The blood sugar initially rises to reach a peak at 30-45 minutes from the start and then falls to reach a nadir at around 120 minutes, usually a little below the initial fasting levels. At or after this time serum levels of growth hormone begin to rise, reaching a a peak at 180 minutes. Those authors considered that a rise of more than $6 \mathrm{ng} / \mathrm{ml}$ serum was normal.

J. P. Cain and colleagues ${ }^{12}$ clarified some confused earlier reports when they compared the effects of giving glucagon by different routes. When glucagon was given as a bolus intravenously, the growth hormone response was virtually immediate and rose with the blood sugar, but this occurred in only about $50 \%$ of normal persons. When it was given subcutaneously the response was more consistent but occurred only after the blood sugar had fallen from its peak; it might be missed if blood samples were not obtained after 90 minutes.

This group of workers has now reported the results of glucagon tests in normal persons and patients with diseases of the pituitary or hypothalamus and has compared these results with those of other tests of growth hormone reserve. ${ }^{13}$ They found that 1 of 20 normal persons failed to show a growth hormone response to $1 \mathrm{mg}$ of subcutaneous glucagon, whereas 3 of 20 failed to respond to intravenous arginine even though the men were pretreated with stilboestrol. These results compared with no false negative results in the 10 persons tested with insulin-induced hypoglycaemia even though these workers used a smaller dose of intravenous insulin than would usually be recommended.

While it seems to be agreed that the glucagon test is rather better and easier to perform than the arginine infusion test, it is hard to agree with the authors that they have shown it to be superior to the insulin tolerance test except when the latter cannot be performed on general medical grounds. Of the patients suspected of hypopituitarism some showed abnormal responses to arginine but normal responses to glucagon, while others who responded to arginine failed to respond to glucagon. Unfortunately none of the patients were tested with insulin-induced hypoglycaemia.

The mechanisms involved in the delayed release of growth hormone after subcutaneous glucagon remain un- 